\title{
Departure from the onset-onset rule
}

\author{
SIU L. CHOW \\ University of Regina, Regina, Saskatchewan, Canada
}

\begin{abstract}
Using a signal-detection task, the generality of Turvey's (1973) onset-onset rule was tested in our experiments. After seeing, in succession, (1) one or two letters (target display), (2) a multiletter detection display, and (3) a mask display, subjects decided whether or not the letter or letters in the target display reappeared in the succeeding detection display at different levels of detection-display duration in various situations. The subjects' sensitivity was inconsistent with the onset-onset rule. More specifically, sensitivity increased with increases in display duration within a fixed stimulus onset asynchrony of $150 \mathrm{msec}$. Display duration, however, had no effect on response bias. Nor was there any interaction between display duration and display size in terms of either sensitivity or response bias. The more complicated relationship between display duration and display size does not invalidate the departure from the onset-onset rule.
\end{abstract}

An experimental procedure commonly used to study the initial stages of visual information processing is to obscure the to-be-processed item (stimulus) by presenting a second item (mask) after stimulus offset, a procedure called backward masking (Kahneman, 1968; Turvey, 1973). At the procedural level, the temporal parameters of interest in such a situation are stimulus duration and interstimulus interval, or ISI (i.e., the interval between the offset of stimulus and the onset of mask). However, the important temporal parameter at the theoretical level is the interval between the onset of stimulus and onset of mask (i.e., the sum of stimulus duration plus ISI), an interval called stimulus onset asynchrony, or SOA (Kahneman, 1968).

SOA is important because perceptual performance improves with increases in SOA (e.g., de Groot, 1984). Moreover, at the theoretical level, SOA represents the amount of time available for processing the stimulus because it is generally accepted that, by virtue of neural persistence, visible persistence, or informational persistence (Coltheart, 1980), processing activities do not cease at the moment the stimulus is withdrawn (Kahneman, 1968; Turvey, 1973). Consequently, the amount of time an observer spends on processing an unmasked 10-msec stimulus may be considerably longer than $10 \mathrm{msec}$. At the same time, backward masking may exert its effects by stopping ongoing activities initiated by the tobe-processed stimulus (Kolers, 1968; Turvey, 1973). Hence, in terms of the "stop-processing" view, SOA is important when it is necessary to have precise control over the exact amount of processing time available to

This research was supported by a grant from the Natural Sciences and Engineering Research Council of Canada. Correspondence concerning this article should be addressed to S. L. Chow, Department of Psychology, University of Regina, Regina, SK, Canada S4S 0A2. subjects (e.g., Loftus, Duncan, \& Gehrig, 1992; Meyer \& Schriefers, 1991; Sereno, 1991).

Cognitive psychologists, however, seem to have ignored the intriguing relationship between SOA and perceptual performance established by Turvey (1973) with the method of limits. Every subject in his Experiment 7 was asked to identify a masked letter in two dichoptic presentation conditions. Stimulus duration was increased after every unsuccessful trial while ISI was held constant in Condition A. Holding stimulus duration constant, he increased ISI after every unsuccessful trial in Condition B.

It was found that, for any given subject, the critical stimulus duration in Condition A was the same as the sum of the experimenter-determined stimulus duration plus the critical ISI in Condition B. That is, letter-identification threshold was not affected by the exact stimulus duration used within a fixed SOA. This relationship is the onsetonset rule, which was further substantiated with the use of consonant-trigram stimuli and a pattern mask in a monoptic presentation situation, in which the mask was weaker than the stimulus (Turvey, 1973, Experiments 12 and 13).

An inherent limitation of using the method of limits is that a threshold value so obtained may be due to either an observer's sensitivity or response bias. Hence, the meaning of the onset-onset rule is not clear. The following four experiments were conducted to evaluate the onset-onset rule by using the theory of signal detection technique in order to determine whether the rule was one about sensitivity or response bias (i.e., an observer's willingness to say "Yes" when uncertain).

\section{GENERAL METHOD}

A detection task was used in all four experiments to be reported. For ease of exposition, general features of the method used in these experiments are described first. Specific variations in these features will be described subsequently when applicable. 


\section{Subjects}

Subjects for all experiments were undergraduate psychology students at the University of Regina. Their vision was normal or corrected to normal. They were informed that the purpose of the experiment was to ascertain how much people could see from a brief stimulus. The subjects were tested individually in multiple sessions. They were paid an honorarium of $\$ 5$ for each session of participation.

\section{Design}

Multifactor factorial designs were used in all experiments. The important control variable was SOA, which was set at $150 \mathrm{msec}$. The design used in data collection included the independent variable response required, whose two levels were Yes and No. This variable was required to categorize subjects' responses as hits and false alarms. The hit and false-alarm rates were used to obtain two separate nonparametric dependent measures, namely, sensitivity (A) and response-bias (B) scores (McNicol, 1972). Since response required disappeared at the level of sensitivity and response bias scores, this variable was absent in data analyses.

\section{Apparatus}

Stimulus displays were prepared and presented with a $386 \mathrm{PC}$ driving a Tektronix Model 108 oscilloscope fitted with P31 phosphor (green) via a high-speed point plotter (Finley, 1985a, 1985b). The subjects were tested under normal room-lighting conditions in order to eliminate any visible trace of the phosphor after stimulus offset. ${ }^{1}$ Timing was controlled and responses were collected with an IBM data-acquisition I/O board. Responses were collected by using a seven-key panel connected to the data-acquisition board. From left to right, the seven keys were labeled as follows: Very Sure Yes, Quite Sure Yes, Guess Yes, Start, Guess No, Quite Sure No, Very Sure No.

\section{Stimulus Materials}

Only uppercase consonants of the English alphabet, except for Y, were used. In Experiments 1-3, a letter was made up of a $7 \times 9$ grid which subtended a visual angle of $32^{\prime}$ (horizontal) $\times 39^{\prime}$ (vertical). In Experiment 4, a smaller $7 \times 9$ grid subtending a visual angle of $21^{\prime}$ (horizontal) $\times 29^{\prime}$ (vertical) was used. The mask display consisted of an array of mask characters made up of the coordinates of the letters A, C, and M. A mask character subtended the same visual angle as the letter M. The " + " symbol was used as the fixation point.

\section{Procedure}

A trial consisted of the presentation (in succession) of a fixation cross, a target display, a multiletter detection display, and a mask display. One letter was used as the target in Experiment 1. The subjects were to respond "Yes" if the target letter reappeared in the detection display; they were to respond "No" if the target did not reappear in the detection display.

Two letters were shown in the target display in Experiments 2-4. The subjects were asked to respond "Yes" if both target letters reappeared in the detection display, regardless of location (i.e., a logical AND signal). The subjects were to respond "No" if only one of the two target letters reappeared in the detection display. It was emphasized to the subjects that at least one of the two target letters was always present in the multiletter detection display. In the course of a session, the left target letter did not reappear in the detection display on No trials on half of the trials; the right target letter did not reappear on the other half. The exact order was determined randomly.

The sequence of events constituting a trial in all experiments was as follows: Presentation of the fixation " + " indicated the onset of a trial. Subjects initiated the target display by pressing the Start key when they were ready. The target display was shown for $1 \mathrm{sec}$. The detection display was shown for a predetermined duration $.5 \mathrm{sec}$ after the offset of the target display. Three levels of detection-display duration were used in all experiments $(25,75$, and $125 \mathrm{msec}$ ). The ISI was adjusted such that the mask display was always presented at an SOA of $150 \mathrm{msec}$. The mask display remained in view until a response was made. It was made less bright than the detection display after the fashion of Turvey's (1973) practice in his Experiments 12 and 13. Subjects indicated how confident they were by pressing an appropriate key.

\section{EXPERIMENT 1}

\section{Method}

There was only one letter in the target display. The subjects were asked to detect its presence in the subsequent detection display. Data collection was based on a $3 \times 3 \times 2$ factorial design. The first factor was detection-display duration (called display duration in subsequent discussion). The second factor was detection-display size (subsequently referred to as display size), whose three levels were 5,7 , and 9 consonants. The third factor was whether the correct answer was Yes or No.

The detection display was in the form of a $3 \times 3$ matrix which subtended a visual angle of $4^{\circ}$ (horizontal) $\times 2.5^{\circ}$ (vertical). Nine consonants filled up all 9 cells. Both the top and bottom rows had two letters when the display size was 5 or 7 . They were in Locations 1 and 3 of the 3-cell row. There was only one letter in the middle when display size was 5 . The middle row had three letters when the display size was 7 . Unused cells were left empty when the detection display size was 5 or 7 . Nine mask characters filled all the cells of the $3 \times 3$ matrix, regardless of display size.

Six subjects were tested individually in two 293-trial sessions. The first 5 trials of every session were warm-up trials. Data from these trials were not included in data analyses. Each of the 18 (display size $\times$ display duration $\times$ response required) treatment combinations was tested 16 times, and these 288 experimental trials were run in a completely randomized order.

\section{Results}

Mean hit and false-alarm rates at each display size $X$ display duration combination are shown in Table 1. Subjects' nonparametric sensitivity (A) and response bias (B) scores were subjected to separate repeated measures $3 \times 3$ analyses of variance (ANOVAs) (i.e., 3 display durations $\times 3$ display sizes). Mean sensitivity and response bias at each treatment combination are depicted in Figure 1. The main effect of display duration was significant $\left[F(2,10)=9.89, M S_{\mathrm{e}}=0.002\right]$. Subjects' mean sensitivity scores were $0.68,0.71$, and 0.74 for durations of 25,75 , and $125 \mathrm{msec}$, respectively (see the top panel of Figure 1). The main effect of display size was also significant $\left[F(2,10)=6.15, M S_{\mathrm{e}}=0.01\right]$. Mean sensitivity scores at Sizes 5,7 , and 9 were $0.72,0.64$, and 0.77 , respectively (see top panel of Figure 1). There was no interaction between display duration and display size.

In the case of response bias, the main effect of display duration was not significant. The main effect of display size, on the other hand, was significant $[F(2,10)=24.29$, $\left.M S_{\mathrm{e}}=0.80\right]$. Means response bias scores were 3.41 , 1.33 , and 2.40, respectively, for Sizes 5, 7, and 9. More- 
Table 1

Hit (H) and False Alarm (FA) Rates in Each Combination of Stimulus Duration and Display Size at Every Level of Confidence Averaged Across Subjects and Sessions (Experiment 1)

\begin{tabular}{|c|c|c|c|c|c|c|c|c|c|c|}
\hline \multirow[b]{2}{*}{ Key* } & \multirow[b]{2}{*}{ Rate } & \multicolumn{3}{|c|}{ Duration $=25 \mathrm{msec}$} & \multicolumn{3}{|c|}{ Duration $=75 \mathrm{msec}$} & \multicolumn{3}{|c|}{ Duration $=125 \mathrm{msec}$} \\
\hline & & Size 5 & Size 7 & Size 9 & Size 5 & Size 7 & Size 9 & Size 5 & Size 7 & Size 9 \\
\hline 1 & $\begin{array}{l}\mathrm{H} \\
\mathrm{FA}\end{array}$ & $\begin{array}{l}0.358 \\
0.122\end{array}$ & $\begin{array}{l}0.368 \\
0.253\end{array}$ & $\begin{array}{l}0.264 \\
0.066\end{array}$ & $\begin{array}{l}0.465 \\
0.059\end{array}$ & $\begin{array}{l}0.493 \\
0.392\end{array}$ & $\begin{array}{l}0.340 \\
0.028\end{array}$ & $\begin{array}{l}0.462 \\
0.080\end{array}$ & $\begin{array}{l}0.576 \\
0.372\end{array}$ & $\begin{array}{l}0.420 \\
0.021\end{array}$ \\
\hline 2 & $\begin{array}{l}\text { H } \\
\text { FA }\end{array}$ & $\begin{array}{l}0.545 \\
0.236\end{array}$ & $\begin{array}{l}0.681 \\
0.569\end{array}$ & $\begin{array}{l}0.576 \\
0.205\end{array}$ & $\begin{array}{l}0.580 \\
0.153\end{array}$ & $\begin{array}{l}0.771 \\
0.642\end{array}$ & $\begin{array}{l}0.615 \\
0.139\end{array}$ & $\begin{array}{l}0.573 \\
0.139\end{array}$ & $\begin{array}{l}0.792 \\
0.611\end{array}$ & $\begin{array}{l}0.653 \\
0.146\end{array}$ \\
\hline 3 & $\begin{array}{l}\text { H } \\
\text { FA }\end{array}$ & $\begin{array}{l}0.691 \\
0.378\end{array}$ & $\begin{array}{l}0.872 \\
0.747\end{array}$ & $\begin{array}{l}0.795 \\
0.507\end{array}$ & $\begin{array}{l}0.656 \\
0.243\end{array}$ & $\begin{array}{l}0.840 \\
0.781\end{array}$ & $\begin{array}{l}0.806 \\
0.438\end{array}$ & $\begin{array}{l}0.649 \\
0.201\end{array}$ & $\begin{array}{l}0.882 \\
0.771\end{array}$ & $\begin{array}{l}0.844 \\
0.434\end{array}$ \\
\hline 4 & $\begin{array}{l}\text { H } \\
\text { FA }\end{array}$ & $\begin{array}{l}0.861 \\
0.681\end{array}$ & $\begin{array}{l}0.979 \\
0.948\end{array}$ & $\begin{array}{l}0.983 \\
0.906\end{array}$ & $\begin{array}{l}0.753 \\
0.420\end{array}$ & $\begin{array}{l}0.944 \\
0.910\end{array}$ & $\begin{array}{l}0.951 \\
0.760\end{array}$ & $\begin{array}{l}0.736 \\
0.375\end{array}$ & $\begin{array}{l}0.955 \\
0.858\end{array}$ & $\begin{array}{l}0.969 \\
0.771\end{array}$ \\
\hline 5 & $\begin{array}{l}\text { H } \\
\text { FA }\end{array}$ & $\begin{array}{l}0.962 \\
0.885\end{array}$ & $\begin{array}{l}1.000 \\
0.997\end{array}$ & $\begin{array}{l}0.997 \\
0.990\end{array}$ & $\begin{array}{l}0.830 \\
0.628\end{array}$ & $\begin{array}{l}0.986 \\
0.972\end{array}$ & $\begin{array}{l}0.990 \\
0.955\end{array}$ & $\begin{array}{l}0.826 \\
0.608\end{array}$ & $\begin{array}{l}0.997 \\
0.972\end{array}$ & $\begin{array}{l}1.000 \\
0.938\end{array}$ \\
\hline 6 & $\begin{array}{l}\mathrm{H} \\
\mathrm{FA}\end{array}$ & $\begin{array}{l}1.000 \\
1.000\end{array}$ & $\begin{array}{l}1.000 \\
1.000 \\
\end{array}$ & $\begin{array}{l}1.000 \\
1.000 \\
\end{array}$ & $\begin{array}{l}1.000 \\
1.000 \\
\end{array}$ & $\begin{array}{l}1.000 \\
1.000 \\
\end{array}$ & $\begin{array}{l}1.000 \\
1.000 \\
\end{array}$ & $\begin{array}{l}1.000 \\
1.000 \\
\end{array}$ & $\begin{array}{l}1.000 \\
1.000 \\
\end{array}$ & $\begin{array}{l}1.000 \\
1.000 \\
\end{array}$ \\
\hline
\end{tabular}

*Keys: 1 = Very Sure Yes, 2 = Quite Sure Yes, $3=$ Guess Yes, 4 = Guess No, 5 = Quite Sure No, and $6=$ Very Sure No.
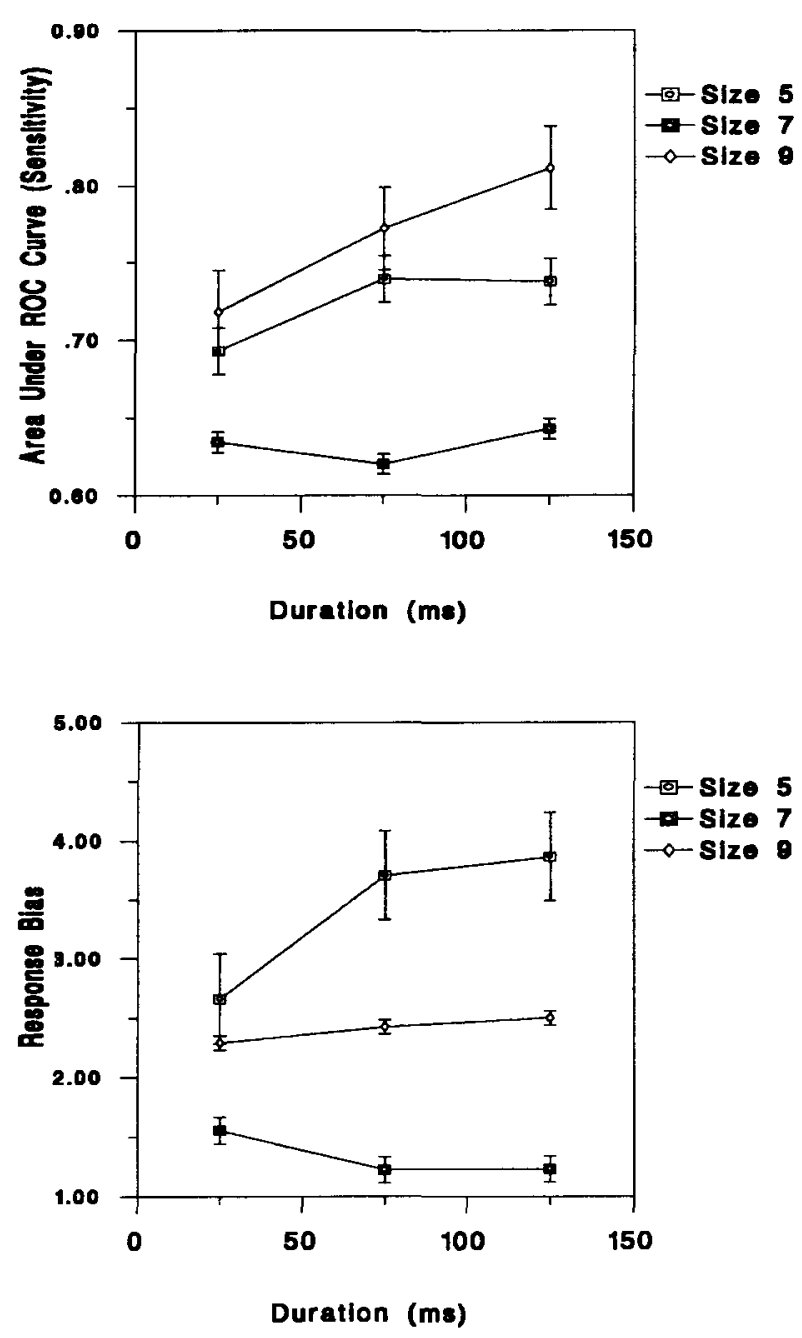

Figure 1. Mean sensitivity (top panel) and response bias (bottom panel) at every display duration and display size combination (Experiment 1). Error bars indicate $1 S E$ above and below the mean. over, the interaction between display duration and display size was significant $\left[F(4,20)=4.36, M S_{\mathrm{e}}=0.25\right]$ (see the bottom panel of Figure 1).

\section{Discussion}

Subjects' sensitivity increased with increases in display duration, despite the fact that SOA was held constant at $150 \mathrm{msec}$. This is a departure from the onsetonset rule. The interaction between display duration and display size when response bias is being considered is primarily due to the fact that subjects became progressively more cautious (i.e., larger B value) at longer durations when the display size was 5 , which was intuitively the easiest among the three display sizes. This suggests that subjects were more cautious when the task was easy (viz, the smallest display size together with the longest display duration). Turvey's (1973) method of limits task might be characterized as an easy one (i.e., there were not too many visual features in a letter or a trigram). Given the stringent criterion he used to terminate a method of limits series (four consecutive correct identifications), his subjects might have adopted a strategy that was cautious enough to obscure the effects of variation in display duration.

\section{EXPERIMENT 2}

Two factors may render suspect the observed departure from the onset-onset rule in Experiment 1. First, the effect of display size seems to be primarily due to lower sensitivity at Display Size 7. This is consistent with neither a serial (Estes \& Taylor, 1966) nor a parallel (Rumelhart, 1970) model of visual information processing. Second, while subjects in Turvey's (1973) study had to identify the to-be-mastered stimulus, subjects in the present Experiment 1 could have performed the single-letter detection task without identifying individual items in the detection display. For example, a single downward- 
Table 2

Hit (H) and False Alarm (FA) Rates in Each Combination of Stimulus Duration and Session at Every Level of Confidence Averaged Across Subjects and Sessions (Experiment 2)

Early Sessions ( 1 and 2) Late Sessions (3 and 4)

Key* Rate $25 \mathrm{msec} 75 \mathrm{msec} 125 \mathrm{msec} 25 \mathrm{msec} 75 \mathrm{msec} 125 \mathrm{msec}$

$\begin{array}{llllllll}1 & \mathrm{H} & 0.063 & 0.073 & 0.094 & 0.044 & 0.060 & 0.102\end{array}$

$\begin{array}{lllllll}\text { FA } & 0.008 & 0.013 & 0.017 & 0.008 & 0.002 & 0.000\end{array}$

$\begin{array}{llllllll}2 & \mathrm{H} & 0.181 & 0.194 & 0.231 & 0.223 & 0.223 & 0.290\end{array}$

$\begin{array}{lllllll}\text { FA } & 0.058 & 0.056 & 0.065 & 0.065 & 0.048 & 0.254\end{array}$

$\begin{array}{llllllll}3 & \mathrm{H} & 0.583 & 0.627 & 0.623 & 0.558 & 0.629 & 0.626\end{array}$

$\begin{array}{lllllll}\text { FA } & 0.354 & 0.373 & 0.365 & 0.329 & 0.281 & 0.256\end{array}$

$\begin{array}{llllllll}4 & \mathrm{H} & 0.965 & 0.954 & 0.946 & 0.973 & 0.983 & 0.931\end{array}$

$\begin{array}{lllllll}\text { FA } & 0.938 & 0.908 & 0.846 & 0.925 & 0.904 & 0.829\end{array}$

$\begin{array}{llllllll}5 & \mathrm{H} & 0.990 & 0.981 & 0.988 & 0.996 & 0.998 & 0.981\end{array}$

$\begin{array}{lllllll}\text { FA } & 0.981 & 0.965 & 0.944 & 0.981 & 0.977 & 0.950\end{array}$

$\begin{array}{llllllll}6 & \mathrm{H} & 1.000 & 1.000 & 1.000 & 1.000 & 1.000 & 1.000\end{array}$

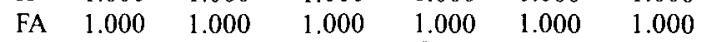

*Keys: $1=$ Very Sure Yes, 2 = Quite Sure Yes, 3 = Guess Yes, $4=$ Guess No, $5=$ Quite Sure No, and $6=$ Very Sure No.

pointing acute angle might be a sufficient cue for detection of the letter "V" in some stimulus arrays.

Hence, it seemed necessary to test the generality of the onset-onset rule with a task in which letter identification was necessary. For these reasons, the logical AND detection task was used. Both target letters reappeared in the detection display half the time. The subjects were to answer "Yes" to these trials. Only one of the two target letters was included in the detection display in the other half of the session. These were the "No" trials.

\section{Method}

Six subjects were tested individually in four 245-trial sessions. The first 5 trials in every session were warm-up trials. There were two letters in the target display, and a seven-letter linear array was used as the detection display which was masked. The two letters in the target display subtended a visual angle of $2.28^{\circ}$ (horizontal) $\times 39^{\prime}$ (vertical). The seven-letter detection array subtended a visual angle of $5.72^{\circ}$ (horizontal) $\times 39^{\prime}$ (vertical).

The subjects had to detect the joint presence in the detection array of the two letters previously shown in the target display. Data were collected in each session with reference to a $3 \times 2$ factorial design. The first independent variable was the three-level display duration. The second variable was response required, whose two levels were Yes and No. The 240 experimental trials were made up of 40 replications of each of the six treatment combinations, and they were presented in a random order.

\section{Results}

Data from Sessions 1 and 2 were collapsed into one set (called early sessions), and those from Sessions 3 and 4 were grouped into another set (called late sessions). The early and late sessions were the two levels of a new independent variable used in the data analyses. Mean hit and false-alarm rates at each combination of display duration and session over all sessions are tabulated in Table 2. Separate repeated measures $3 \times 2$ factorial ANOVAs were carried out to determine sensitivity and response bias. Mean sensitivity and response bias in each of the six display duration $\times$ session combinations are depicted in Figure 2.
In the case of sensitivity, only the factor of display duration was significant $\left[F(2,10)=14.19 ; M S_{\mathrm{e}}=0.007\right]$. Mean sensitivity scores were $0.64,0.68$, and 0.71 for display durations of 25,75 , and $125 \mathrm{msec}$, respectively (see top panel of Figure 2). As for response bias, ANOVA yielded neither any main effect nor an interaction between display duration and session (see the bottom panel of Figure 2).

\section{Discussion}

A departure from the onset-onset rule was found in this experiment when display size was not manipulated. This observation supports the conclusion that the departure observed in Experiment 1 in terms of sensitivity was not due to the unusual display-size effect. Letter identification was required to perform the logical AND task used in this experiment. Yet, a departure from the onset-onset rule was observed. It means that the departure observed in Experiment 1 cannot be explained in terms of differences between the tasks used by Turvey
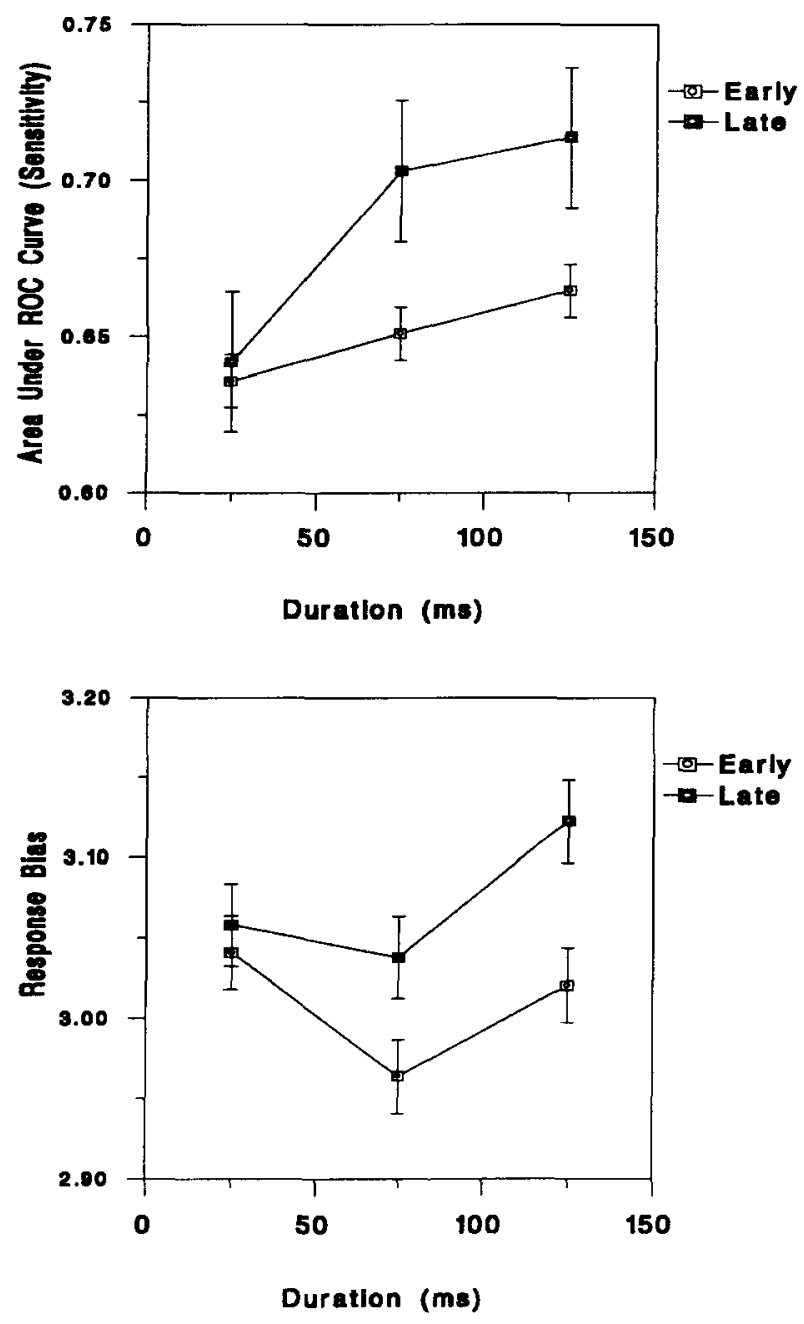

Figure 2. Mean sensitivity (top panel) and response bias (bottom panel) at every display duration and session combination (Experiment 2). Error bars indicate $1 S E$ above and below the mean. 
Table 3

Hit (H) and False Alarm (FA) Rates in Each Combination of Stimulus Duration and Yes:No Ratio at Every Level of Confidence Averaged Across Subjects and Sessions (Experiment 3)

\begin{tabular}{|c|c|c|c|c|c|c|c|c|c|c|}
\hline \multirow[b]{2}{*}{ Key* } & \multirow[b]{2}{*}{ Rate } & \multicolumn{3}{|c|}{ Yes: No Trials $=40: 60$} & \multicolumn{3}{|c|}{ Yes: No Trials $=50: 50$} & \multicolumn{3}{|c|}{ Yes: No Trials $=60: 40$} \\
\hline & & $25 \mathrm{msec}$ & $75 \mathrm{msec}$ & $125 \mathrm{msec}$ & $25 \mathrm{msec}$ & $75 \mathrm{msec}$ & $125 \mathrm{msec}$ & $25 \mathrm{msec}$ & $75 \mathrm{msec}$ & $125 \mathrm{msec}$ \\
\hline \multirow[t]{2}{*}{1} & $\mathrm{H}$ & 0.039 & 0.057 & 0.074 & 0.042 & 0.063 & 0.079 & 0.046 & 0.065 & 0.097 \\
\hline & FA & 0.008 & 0.012 & 0.002 & 0.006 & 0.017 & 0.000 & 0.003 & 0.006 & 0.009 \\
\hline \multirow[t]{2}{*}{2} & $\mathrm{H}$ & 0.241 & 0.229 & 0.321 & 0.262 & 0.296 & 0.323 & 0.262 & 0.282 & 0.321 \\
\hline & $\mathrm{FA}$ & 0.103 & 0.117 & 0.071 & 0.115 & 0.108 & 0.079 & 0.107 & 0.083 & 0.074 \\
\hline \multirow[t]{2}{*}{3} & $\mathrm{H}$ & 0.637 & 0.595 & 0.637 & 0.629 & 0.604 & 0.600 & 0.619 & 0.647 & 0.643 \\
\hline & FA & 0.389 & 0.397 & 0.260 & 0.410 & 0.379 & 0.275 & 0.390 & 0.348 & 0.301 \\
\hline \multirow[t]{2}{*}{4} & $\mathrm{H}$ & 0.961 & 0.949 & 0.893 & 0.944 & 0.919 & 0.871 & 0.954 & 0.942 & 0.911 \\
\hline & FA & 0.877 & 0.845 & 0.683 & 0.910 & 0.844 & 0.681 & 0.896 & 0.804 & 0.723 \\
\hline \multirow[t]{2}{*}{5} & $\mathrm{H}$ & 1.000 & 1.000 & 0.994 & 1.000 & 0.996 & 0.988 & 1.000 & 0.992 & 0.992 \\
\hline & FA & 0.994 & 0.984 & 0.950 & 0.990 & 0.992 & 0.942 & 0.991 & 0.979 & 0.949 \\
\hline \multirow[t]{2}{*}{6} & $\mathrm{H}$ & 1.000 & 1.000 & 1.000 & 1.000 & 1.000 & 1.000 & 1.000 & 1.000 & 1.000 \\
\hline & FA & 1.000 & 1.000 & 1.000 & 1.000 & 1.000 & 1.000 & 1.000 & 1.000 & 1.000 \\
\hline
\end{tabular}

*Keys: 1 = Very Sure Yes, $2=$ Quite Sure Yes, $3=$ Guess Yes, $4=$ Guess No, $5=$ Quite Sure No, and $6=$ Very Sure No.
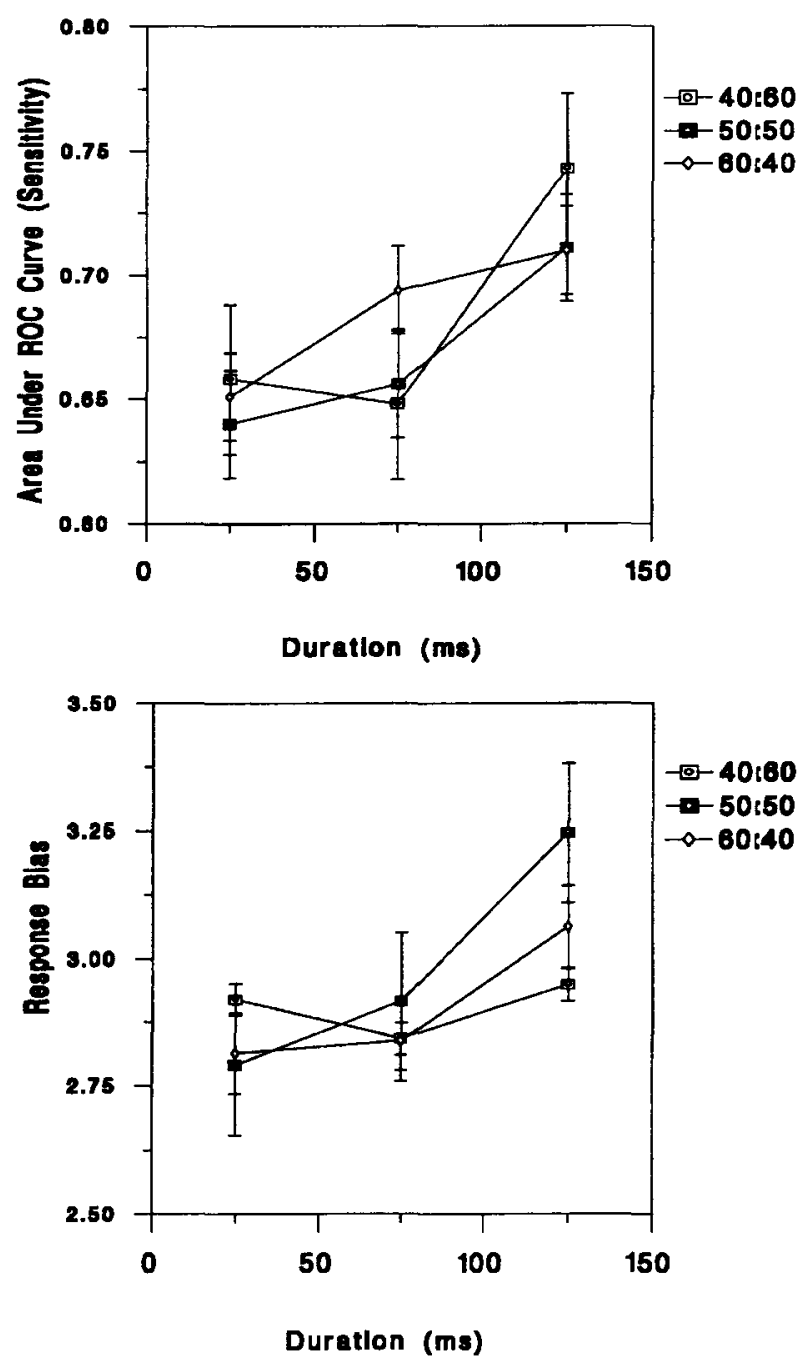

Figure 3. Mean sensitivity (top panel) and response bias (bottom panel) at every display duration and Yes: No ratio combination (Experiment 3). Error bars indicate $1 S E$ above and below the mean. terms of differences between the tasks used by Turvey (1973) and the detection task used.

\section{EXPERIMENT 3}

Neither of the manipulations used in Experiments 1 and 2 was directly related to response bias. The objective of Experiment 3 was to determine whether or not it was possible to obtain a departure from the onset-onset rule in terms of response bias by manipulating the proportion of Yes trials in a session. Hence, the independent variable, Yes-No ratio, was used at three levels, namely, 40:60 (40 Yes to 60 No trials), 50:50, and 60:40.

\section{Method}

Subjects were given the logical AND detection task in which the detection display was a 7-letter array. Every experimental session was conducted with reference to a $3 \times 3 \times 2$ factorial design. The first variable was Yes-No ratio, the second was display duration, and the last was whether it was a Yes or No trial. There were 210 , 240 , and 210 experimental trials in the 40:60,50:50, and 60:40 conditions, respectively.

Every subject participated in six sessions, two sessions under each of the three Yes-No ratio conditions. Six subjects were randomly divided into three pairs. Subjects in each of three pairs received the three levels of Yes-No ratio in a different order according to a Latin square. The subjects were informed of the Yes-No ratio at the beginning of every session. Other aspects of this experiment were identical to those of Experiment 2.

\section{Results}

Data from the two sessions devoted to the same Yes-No ratio condition were collapsed before the nonparametric sensitivity and response bias scores were calculated. Mean hit and false-alarm rates for each of the nine display duration and Yes-No ratio combinations are tabulated in Table 3. Separate repeated measures $3 \times 3$ factorial ANOVAs were conducted for the sensitivity and response-bias scores. The first factor was the Yes-No ratio. The second was display duration. Mean sensitivity and response scores for each display duration and Yes--No ratio combination are shown in Figure 3. 
In the case of sensitivity, there was no effect of Yes-No ratio. Only the factor display duration was significant $\left[F(2,6)=15.97, M S_{\mathrm{e}}=0.002\right]$. The mean sensitivity scores for durations of 25,75 , and $125 \mathrm{msec}$ were 0.65 , 0.67 , and 0.73 , respectively (see top panel of Figure 3 ). The interaction between display duration and Yes-No ratio was not significant. And in the case of response bias, there was no main effect of display duration, no main effect of Yes-No ratio, and no significant interaction between the two (see bottom panel of Figure 3).

\section{EXPERIMENT 4}

The departure from the onset-onset rule observed so far was obtained with visual displays whose visual angle was wider than foveal vision. The reason for the choice of visual angle was to minimize the effects of lateral inhibition. As the same visual angle was used at all levels of stimulus duration, the observed effect of duration could not be due to the unusually large visual angle. Be that as it may, it seemed necessary to examine the joint effects of display duration and display size with a visual angle that was appropriate for foveal vision. Consequently, the subjects were tested with the logical AND detection task used in Experiments 2 and 3 with a smaller $3 \times 3$ detection display.

\section{Method}

Data were collected with reference to the $3 \times 3 \times 2$ factorial design used in Experiment 1. When the detection display consisted of 9 letters, they were shown in three rows of three letters each. This display subtended a visual angle of $1.93^{\circ}$ (horizontal) $\times 1.58$ (vertical). These vertical and horizontal dimensions were also used for the 5- and 7-letter displays. However, unlike the case in Experiment 1, the 5 or 7 letters in the Size 5 or Size 7 condition were distributed randomly within the $3 \times 3$ matrix. Unused cells were left empty. The mask display was made up of 9 mask characters which filled up all cells of the $3 \times 3$ matrix, regardless of display size. The 2-letter target display subtended a visual angle of $1.15^{\circ}$ (horizontal) $\times 29^{\prime}$ (vertical). The subjects were tested individually in two sessions. Features related to the logical AND task were the same as those found in Experiments 2 and 3. All other features of the procedure used were the same as those found in Experiment 1.

\section{Results}

As in Experiment 1, separate repeated measures $3 \times 3$ ANOVAs were carried out to determine sensitivity and response bias. Mean hit and false-alarm rates at each of the nine display duration and display size combinations are shown in Table 4. Mean sensitivity and response bias at each of the nine treatment combinations are depicted in Figure 4. In the case of sensitivity, the analysis revealed a significant main effect of display duration $[F(2,10)=$ $\left.5.03, M S_{\mathrm{e}}=0.003\right]$. Mean sensitivity scores for durations of 25,75 , and $125 \mathrm{msec}$ were $0.67,0.72$, and 0.73 , respectively (see top panel of Figure 4). The main effect of display size was also significant $[F(2,10)=15.77$, $\left.M S_{\mathrm{e}}=0.004\right]$. Mean sensitivity scores for Sizes 5,7 , and 9 were $0.77,0.70$, and 0.65 , respectively. There was no interaction between display duration and display size. In the case of response bias, none of the main effects were significant (see bottom panel of Figure 4). Nor was the interaction between display duration and display size significant in terms of response bias.

\section{GENERAL DISCUSSION}

The visual angle subtended by the detection displays used in Experiments 1-3 were wider than what could be accommodated by foveal vision. That a departure from the onset-onset rule was still observed when a display size compatible with foveal vision was used suggests that the departure was not due to the choice of visual angle.

Table 4

Hit (H) and False Alarm (FA) Rates in Each Combination of Stimulus Duration and Display Size at Every Level of Confidence Averaged Across Subjects and Sessions (Experiment 4)

\begin{tabular}{|c|c|c|c|c|c|c|c|c|c|c|}
\hline \multirow[b]{2}{*}{ Key* } & \multirow[b]{2}{*}{ Rate } & \multicolumn{3}{|c|}{ Duration $=25 \mathrm{msec}$} & \multicolumn{3}{|c|}{ Duration $=75 \mathrm{msec}$} & \multicolumn{3}{|c|}{ Duration $=125 \mathrm{msec}$} \\
\hline & & Size 5 & Size 7 & Size 9 & Size 5 & Size 7 & Size 9 & Size 5 & Size 7 & Size 9 \\
\hline \multirow[t]{2}{*}{1} & $\mathrm{H}$ & 0.328 & 0.240 & 0.151 & 0.359 & 0.193 & 0.188 & 0.448 & 0.234 & 0.203 \\
\hline & FA & 0.083 & 0.078 & 0.057 & 0.078 & 0.073 & 0.063 & 0.063 & 0.063 & 0.057 \\
\hline \multirow[t]{2}{*}{2} & $\mathrm{H}$ & 0.583 & 0.536 & 0.667 & 0.641 & 0.453 & 0.448 & 0.677 & 0.536 & 0.458 \\
\hline & FA & 0.276 & 0.229 & 0.234 & 0.224 & 0.245 & 0.219 & 0.167 & 0.193 & 0.260 \\
\hline \multirow[t]{2}{*}{3} & $\mathrm{H}$ & 0.750 & 0.755 & 0.761 & 0.818 & 0.682 & 0.734 & 0.786 & 0.766 & 0.693 \\
\hline & FA & 0.438 & 0.438 & 0.552 & 0.344 & 0.401 & 0.438 & 0.286 & 0.396 & 0.526 \\
\hline \multirow[t]{2}{*}{4} & $\mathrm{H}$ & 0.891 & 0.875 & 0.880 & 0.896 & 0.849 & 0.917 & 0.870 & 0.896 & 0.870 \\
\hline & FA & 0.672 & 0.677 & 0.833 & 0.536 & 0.625 & 0.750 & 0.484 & 0.682 & 0.734 \\
\hline \multirow[t]{2}{*}{5} & $\mathrm{H}$ & 0.958 & 0.974 & 0.979 & 0.943 & 0.974 & 0.984 & 0.948 & 0.984 & 0.964 \\
\hline & FA & 0.833 & 0.896 & 0.964 & 0.781 & 0.917 & 0.958 & 0.724 & 0.875 & 0.948 \\
\hline \multirow[t]{2}{*}{6} & $\mathrm{H}$ & 1.000 & 1.000 & 1.000 & 1.000 & 1.000 & 1.000 & 1.000 & 1.000 & 1.000 \\
\hline & FA & 1.000 & 1.000 & 1.000 & 1.000 & 1.000 & 1.000 & 1.000 & 1.000 & 1.000 \\
\hline
\end{tabular}

*Keys: 1 = Very Sure Yes, 2 = Quite Sure Yes, 3 = Guess Yes, 4 = Guess No, 5 = Quite Sure No, and $6=$ Very Sure No. 

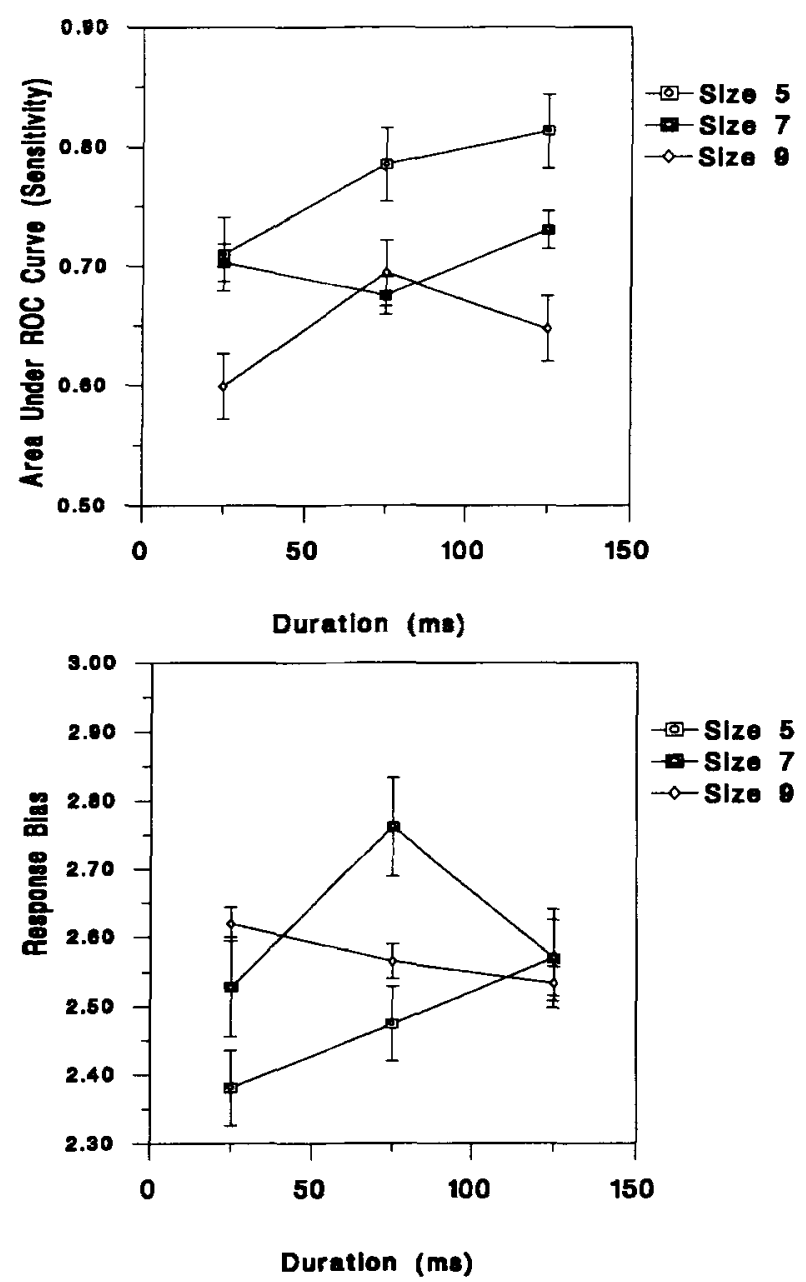

Figure 4. Mean sensitivity (top panel) and response bias (bottom panel) at every display duration and display size combination (Experiment 4). Error bars indicate $1 S E$ above and below the mean.

Two factors might be responsible for the unusual relationship between display size and sensitivity in Experiment 1 . First, the detection display subtended an unusually large visual angle. Second, given the format of the display, a 9-letter display might be more "cohesive" than a 5- or 7-letter display. For example, the middle row was sandwiched between two incomplete rows in a 7 letter array. An elementary figure-ground process might turn a 7-letter display effectively into one made up of separate smaller displays. As a distinctive "figure" within the detection display, the middle row might have captured subjects' attention. Consequently, their detection performance suffered if the target letter reappeared elsewhere, that is, other than in the middle row. Suggestive of these two possibilities is the systematic decrease in sensitivity with increases in display size in Experiment 4 , a finding more in line with other studies of detection performance (Estes \& Taylor, 1966). What is important is that a departure from the onset-onset rule was observed, regardless of whether the relationship between display size and sensitivity was irregular (Experiment 1) or regular (Experiment 4).

The present series of experiments began with the empirical question as to whether the onset-onset rule reflected a property of the visual system or an individual's strategy. The observed departure from the onset-onset rule in terms of sensitivity in various situations renders more obvious its paradigmatic importance, as well as its limitations. The onset-onset rule was based on observers' letter-identification thresholds. It describes the minimal amount of time required by an individual to identify a specific linguistic unit (e.g., a letter, a trigram, etc.). However, it is not informative as to how this minimal amount of processing time is divided among the various processing activities (e.g., feature registration and establishing letter identity), particularly when the time available for processing exceeds the letter-identification threshold. The present data suggest that the departure from the onset-onset rule may profitably be used to investigate theoretical properties of the early stages of visual information processing.

\section{REFERENCES}

Coltheart, M. (1980). Iconic memory and visible persistence. Perception \& Psychophysics, 27, 183-228.

DE Groot, A. M. B. (1984). Primed lexical decision: Combined effects of the proportion of related prime-target pairs and the stimulusonset asynchrony of prime and target. Quarterly Journal of Experimental Psychology, 36, 253-280.

ESTES, W. K., \& TAYLOR, H. A. (1966). Visual detection in relation to display size and redundancy of critical elements. Perception \& Psychophysics, 1, 9-16.

FINLEY, G. (1985a). A high-speed point plotter for vision research. $V i-$ sion Research, 25, 1993-1997.

FINLEY, G. (1985b). Laboratory functions for the Tecmar Lab Tender and IBM PC. Behavior Research Methods, Instruments, \& Computers, 17, 397-398.

KAHNEMAN, D. (1968). Method, findings, and theory in studies of visual masking. Psychological Bulletin, 70, 404-425.

Kolers, P. (1968). Some psychological aspects of pattern recognition. In P. A. Kolers \& M. Eden (Eds.), Recognizing patterns (pp. 4-61). Boston: MIT Press.

Lofrus, G. R., DunCan, J., \& Gehrig, P. (1992). On the time course of perceptual information that results from brief visual presentation. Journal of Experimental Psychology: Human Perception \& Performance, $18,540-549$.

MCNICOL, D. (1972). A primer of signal detection theory. London: Allen \& Unwin.

Meyer, A. S., \& Schriefers, H. (1991). Phonological facilitation in picture-word interference experiments: Effects of stimulus onset asynchrony and types of interfering. Journal of Experimental Psychology: Learning, Memory, \& Cognition, 17, 1146-1160.

Mollon, J. D., \& Polden, P. G. (1978). On the time constants of tachistoscopes. Quarterly Journal of Experimental Psychology, 30, 555-568.

RUMELHART, D. E. (1970). A multicomponent theory of the perception of briefly exposed visual displays. Journal of Mathematical Psychology, 7, 191-218.

SERENO, J. A. (1991). Graphemic, associative, and syntactic priming effects at a brief stimulus onset asynchrony in lexical decision and naming. Journal of Experimental Psychology: Learning, Memory, \& Cognition, 17, 459-477.

TuRVeY, M. T. (1973). On peripheral and central processes in vision: Inferences from an information-processing analysis of masking with patterned stimuli. Psychological Review, 80, 1-52. 


\section{NOTE}

1. Some investigators may find the decay characteristics of $P 31$ phosphor wanting because one of its two traces decays more slowly than the other. Their phosphor of choice is P4. A practical solution for someone using P31 phosphor seems to be to use it under normal lighting conditions. The relatively slow decaying trace should no longer be problematic if it is made invisible. This strategy is less questionable if it is realized that other modes of stimulus presentation may have their own problems. For example, the timing control of tachistoscopes is not as exact as it is commonly believed to be (Mollon \& Poldon, 1978). The best justification for using P3 I to study the onset-onset rule, however, is a logical one. The slow-decaying trace of the phosphor makes it easier to obtain data consistent with the onset-onset rule if it affects perceptual performance even when it is invisible under normal lighting conditions. This is because shorter durations are effectively longer than envisioned; and because of the mask, the longer durations are not as beneficial as shorter durations. In other words, the slow-decaying phosphor trace renders it more difficult to establish the observation that sensitivity increases with display duration within a fixed SOA.

That is to say, a departure from the onset-onset rule obtained with the P31 phosphor cannot be explained in terms of the characteristics of the phosphor's decaying traces.

(Manuscript received October 29, 1993; accepted for publication November 29, 1993.) 